\title{
Unusually located metallic foreign body in posterior chamber of eyeball: role of multimodal ocular imaging in its diagnosis and management
}

\author{
Rinky Agarwal (10,' Manasi Tripathi, ${ }^{1}$ Bhavika Bansal, ${ }^{2}$ Anuja Patil ${ }^{1}$
}

'Ophthalmology, All India Institute of Medical Sciences, New Delhi, Delhi, India ${ }^{2}$ All India Institute of Medical Sciences, New Delhi, Delhi, India

\section{Correspondence to} Dr Rinky Agarwal; rinky.1990@gmail.com

Accepted 30 September 2020

Check for updates

(C) BMJ Publishing Group Limited 2020. No commercial re-use. See rights and permissions. Published by BMJ.

\begin{tabular}{l|}
\hline To cite: Agarwal R, \\
Tripathi M, Bansal B, \\
et al. BMJ Case Rep \\
2020;13:e239345. \\
doi:10.1136/bcr-2020- \\
239345 \\
\hline
\end{tabular}

\section{DESCRIPTION}

Intraocular foreign bodies (FBs) are extraneous objects usually detected in the eyeball after trauma with metallic objects. As these can cause sightthreatening complications such as endophthalmitis and siderosis bulbi, early diagnosis and removal are essential for favourable outcome. However, sometimes, despite the presence of a characteristic history, it may be difficult to visualise FBs located in unusual location making their diagnosis and management challenging. ${ }^{1}$

A 24-year-old systemically healthy male, welder by occupation and having characteristic history of hammer and chisel injury to right eye 30 days back, was referred for removal of radio-opaque FB appreciated on X-ray orbit. Visual acuity was 20/20 in both eyes and right eye showed a $1.5 \mathrm{~mm}$ linear corneal scar at 7'O clock position with a patch of underlying iris fibrosis (figure 1A). The patient was visually asymptomatic and there was no cataract or other signs of iris damage suggestive of additional iris penetration by a FB. Slit-lamp biomicroscopy even with the aid of Goldmann 2-mirror gonioprism (figure 1B,C) or anterior segment optical coherence tomography (ASOCT) did not demonstrate any FB. Non-contrast computerised tomography (NCCT) scan of head and orbits ( $2 \mathrm{~mm}$ slice thickness) revealed a $4 \times 4 \mathrm{~mm}$ radio-opaque $\mathrm{FB}$ localised to the inferotemporal region of eyeball near the ciliary body (figure 1D,E). High-frequency ultrasound biomicroscopy (UBM) localised the FB to posterior chamber (figure 1F). A normal electroretinogram ruled out any siderotic changes (figure $1 G$ ). The reason for his delayed presentation to our centre was his geographically distant location, good visual acuity and frequent visits to multiple private practitioners for removal of radiologically visible but clinically hidden FB. After obtaining written informed consent, a $1.5 \times 2 \mathrm{~mm}$ FB was successfully removed from the anterior route using 23 -gauge microvitrectomy forceps after dissection of overlying iris with Sinskey hook. The extracted FB was identified as metallic by a magnet and iron containing on forensic examination (figure 2A). Repeat CT scan did not show any residual FB (figure $2 \mathrm{~B}$ ). The patient was prescribed antibiotics-steroid-cycloplegic for 7 days and at 3 months follow-up, visual acuity was wellmaintained with no signs of siderosis.

Various investigations used to localise FBs in the ciliary body region include gonioscopy, NCCT, ASOCT and UBM. ${ }^{1-4}$ Grafii had reported an iron FB in the zonular area, which was primarily hidden in inferior chamber angle, and slipped there during surgical manipulation. ${ }^{1}$ In the presently discussed first reported case of primary presentation of $\mathrm{FB}$ in the zonular area, while X-ray could detect presence of a radio-opaque FB, slit lamp biomicroscopy, gonioscopy and ASOCT all failed to recognise it due to its uncommon location and overlying fibrotic iris. Though NCCT played an indispensable role in determining the site and type (metallic vs nonmetallic) of FB, it failed to provide finer details for surgical removal and UBM served as an extremely helpful modality by providing a magnified view of the intraocular structures and localising the FB to posterior chamber in the present case. While all these provided anatomical details, electroretinogram quantified its functional effects.

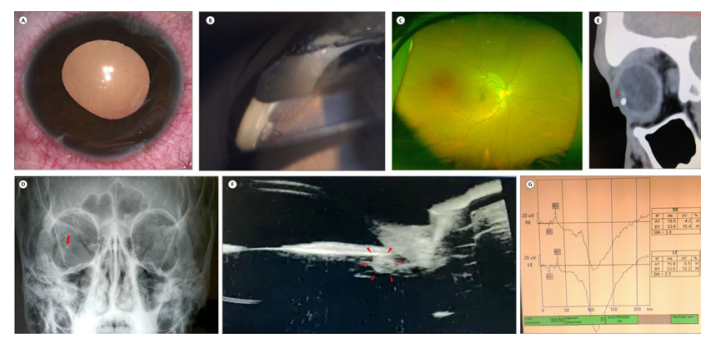

Figure 1 FB hidden from view by corneal scar and fibrotic iris on slit-lamp biomicroscopy $(A)$ and on gonioscopy (B); normal fundus (C); FB (red arrows) as seen on X-ray (D); NCCT scan (E) and UBM (F), respectively; normal photopic and scotopic electroretinogram (G). FB, foreign body; NCCT, noncontrast computerised tomography; UBM, ultrasound biomicroscopy.
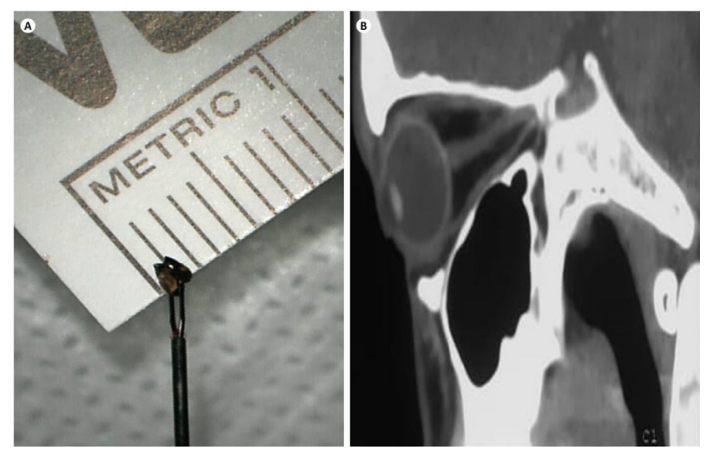

Figure 2 Extracted metallic $F B(A)$; and postoperative absence of FB on NCCT scan (B). FB, foreign body; NCCT, non-contrast computerised tomography. 
In such complex cases of FBs hidden in unusual location like posterior chamber of eyeball, multimodal ocular imaging plays a pivotal role in diagnosing, prognosticating and surgical planning of the case. As seen presently, delay in presentation may allow healing of iris defects, if any, which may make localisation of FB even more challenging. As characteristic history and radiographic examination suggested the metallic nature of FB in our case, we planned its removal to prevent subsequent ocular siderosis, a grave complication seen with retained intraocular metallic FBs. Ocular siderosis may be seen in around $83.33 \%$ patients with metallic FBs and the period between the ocular injury and its diagnosis may range from 1 to 240 months. The condition progresses slowly over years and the visual outcome is usually unpredictable. However, surgical treatment can improve the

\section{Learning points}

- Foreign bodies (FBs) present in posterior chamber of eyeball are challenging to diagnose despite a characteristic history of metallic FB trauma.

- Various investigations such as gonioscopy, non-contrast $\mathrm{CT}$, anteriorsegment optical coherence tomography and ultrasound biomicroscopy (UBM) must all be used in combination for best results.

- UBM can serve as an extremely helpful modality in such cases by providing a magnified view of the intraocular structures and localising the FB to posterior chamber. visual rehabilitation in 63\% cases and therefore early removal of iron-containing FBs, as undertaken in our case, is recommended. ${ }^{5}$

To conclude, if a similar situation is encountered at a primary eye-care centre, it is advisable to perform a baseline X-ray and immediately refer the patient to higher centre to prevent siderosis and subsequent visual loss, particularly if the patient's history is characteristic of metallic FB trauma.

Contributors RA helped in patient care, data collection and manuscript writing. MT helped in patient care. BB helped in data collection. AP performed manuscript editing.

Funding The authors have not declared a specific grant for this research from any funding agency in the public, commercial or not-for-profit sectors.

Competing interests None declared.

Patient consent for publication Obtained.

Provenance and peer review Not commissioned; externally peer reviewed.

\section{ORCID iD}

Rinky Agarwal http://orcid.org/0000-0002-4576-4915

\section{REFERENCES}

1 Graffi S, Tiosano B, Ben Cnaan R, et al. Foreign body embedded in anterior chamber angle. Case Rep Ophthalmol Med 2012;2012:1-3.

2 Dass $A B$, Ferrone PJ, Chu YR, et al. Sensitivity of spiral computed tomography scanning for detecting intraocular foreign bodies. Ophthalmology 2001;108:2326-8.

3 Mahmoud A, Messaoud R, Abid F, et al. Anterior segment optical coherence tomography and retained vegetal intraocular foreign body masquerading as chronic anterior uveitis. J Ophthalmic Inflamm Infect 2017;7:13.

4 Kaushik S, Ichhpujani P, Ramasubramanian A, et al. Occult intraocular foreign body: ultrasound biomicroscopy holds the key. Int Ophthalmol 2008;28:71-3.

5 Zhu L, Shen P, Lu H, et al. Ocular trauma score in siderosis bulbi with retained intraocular foreign body. Medicine 2015;94:e1533.

Copyright 2020 BMJ Publishing Group. All rights reserved. For permission to reuse any of this content visit https://www.bmj.com/company/products-services/rights-and-licensing/permissions/

BMJ Case Report Fellows may re-use this article for personal use and teaching without any further permission.

Become a Fellow of BMJ Case Reports today and you can:

- Submit as many cases as you like

- Enjoy fast sympathetic peer review and rapid publication of accepted articles

- Access all the published articles

Re-use any of the published material for personal use and teaching without further permission

Customer Service

If you have any further queries about your subscription, please contact our customer services team on +44 (0) 2071111105 or via email at support@bmj.com.

Visit casereports.bmj.com for more articles like this and to become a Fellow 